\title{
Sieving alive or after fixation: effects of sieving procedure on macrobenthic diversity, density and community structure
}

\author{
S. Degraer • I. Moulaert • G. Van Hoey • M. Vincx
}

Received: 28 September 2006 / Revised: 29 January 2007 / Accepted: 30 January 2007 / Published online: 24 March 2007

(C) Springer-Verlag and AWI 2007

\begin{abstract}
Although combining datasets is often needed to unravel large-scale or long-term patterns in benthos ecology, this is frequently hampered by differences in technical design of the individual studies. One element that often vary among macrobenthic studies is the sieving procedure: sieving alive versus sieving after fixation. This study therefore aimed at the qualification and quantification of the impact of sieving procedure, using a $1 \mathrm{~mm}$ mesh sized sieve, at three levels of ecological organisation: (1) diversity, (2) species and taxon density, and (3) community structure. To include a maximum suite of macrobenthic species and to evaluate the community-specific effects, the impact of sieving procedure was investigated within four widely spread macrobenthos communities in the Belgian part of the North Sea. Sieving alive negatively impacted all tested diversity measures $\left(\mathrm{S}, \mathrm{N}_{1}, \mathrm{~N}_{2}, \mathrm{~N}_{\infty}, \mathrm{H}^{\prime}, \mathrm{E} S_{100}\right.$ and $\mathrm{J}^{\prime}$ ): community-dependent relative losses of up to $35 \%$ were observed. However, most trends were ambiguous and statistically non-significant. Community- and taxon-dependent impacts were detected at the level of density. Mainly polychaetes were found to be negatively impacted by sieving alive (relative losses maximum $81 \%$ ): especially small, interstitial polychaetes
\end{abstract}

Communicated by H.-D. Franke.

S. Degraer $(\bowtie) \cdot$ I. Moulaert · G. Van Hoey $\cdot$ M. Vincx

Biology Department, Marine Biology Section,

Ghent University, Krijgslaan 281-S8, 9000 Gent, Belgium

e-mail: Steven.Degraer@UGent.be

\section{Moulaert}

Institute for Agricultural and Fisheries Research,

Animal Sciences, Fisheries, Ankerstraat 1,

8400 Oostende, Belgium (e.g. Hesionura elongata and Spio filicornis) tend to actively escape from the sieve (relative loss up to $100 \%)$. Next to size, also behaviour, the presence of head appendages, the depth of the sampling stations and sampling season are believed to influence the sieving procedure impact. While detailed community composition was impacted (ANOSIM dissimilarity: maximum $85 \%$ ), no major impact on the differentiation between the investigated communities was detected. The present study thus demonstrated that combining data, retrieved with a different sieving procedure can be useful, but its reliability will mainly depend on the type of questions one wants to answer. In all cases caution at all levels of ecological organisation is advised.

Keywords Sieving procedure $\cdot$ Fixation $\cdot$

Macrozoobenthos

\section{Introduction}

The technical design of soft-sediment macrozoobenthos studies can vary substantially, depending on study-specific objectives (Bilyard et al. 1987). Variations in the elements that constitute such a study design can influence the comparability of different data sets. Some elements that vary among studies and that have already been studied intensively are the sampling devices (Thorson 1957; Eleftheriou and Holme 1984; Bilyard et al. 1987; Long and Wang 1994), sample replication (McIntyre et al. 1984; Bilyard et al. 1987), sieve mesh size (Eleftheriou and Holme 1984; Bilyard et al. 1987; Ohwada 1988; Bachelet 1990; James et al. 1995; Gage et al. 2002; Thompson et al. 2003) and level of 
taxonomic discrimination (Bilyard et al. 1987; James et al. 1995; Gage et al. 2002; Thompson et al. 2003).

Another important element that may vary among studies, is the sieving procedure: sieving before fixation (animals still alive while sieving) versus after fixation (animals dead). In most benthic studies sieving is done before fixation of the sample (e.g. Thorson 1957; Dybern et al. 1976; Eleftheriou and Holme 1984; James et al. 1995; Elliott et al. 1996; Pohle and Thomas 1997; Degraer et al. 1999; Cooper and Boyd 2002; Degraer et al. 2003; Van Hoey et al. 2004), as recommended through the EU-SMT Programme BEQUALM (SMT4-CT98-2241). Only in few studies the samples were sieved after they had been fixated (Govaere 1978; Vanosmael et al. 1982; Bachelet 1990; Thompson et al. 2003). This bias in sieving procedure can be largely assigned to the choice between the retention of as much species and individuals as possible (sieving after fixation) and the avoidance of environmental contamination with large volumes of formalin (sieving alive). While numerous authors mentioned that, for certain species, an actual impact of sieving procedure should be expected (Thorson 1957; Govaere 1978; Bilyard et al. 1987; Bachelet 1990; Rumohr 1990; Gage et al. 2002; Van Hoey et al. 2004), little research was done on the qualification and quantification of the difference in sieving procedure. In his study on the effect or sieving procedure on the benthos retained with a $0.5 \mathrm{~mm}$ mesh sized sieve, Ohwada (1988) reported that polychaetes might be far more abundant (up to 20 times) in samples sieved after fixation compared to samples sieved alive. Sieving procedure thus has a major impact on the observed species densities and consequently also diversity and community structure.

While sieving procedure is generally kept constant throughout each study, the effect of sieving procedure becomes a problem when trying to combine datasets from different studies. Combined datasets are often needed to unravel large-scale or long-term patterns in benthos ecology (e.g. Künitzer et al. 1992; Rees et al. 2002; Van Hoey et al. 2004). In these cases it is of utmost importance to know how exactly sieving procedure impacts the observed spatial or temporal patterns.

This study aims at the qualification and quantification of the effects of sieving procedure at three levels of ecological organisation, commonly used within benthos research: (1) diversity, (2) species and higher taxa densities, and (3) community structure. At the diversity level the effect of sieving procedure was investigated on a suite of commonly used diversity measures. Species- and taxon-specific effects on density were quantified and correction models were explored at the taxon level. At the level of community structure the effects of sieving procedure on the outcome of multivariate analyses were analysed.

While the prime applicability of the species-specific quantification of the effects is regional (southern North Sea), the effects at the level of diversity, taxon density or community structure are considered to be applicable at a wider scale.

\section{Materials and methods}

\section{Sampling site}

All samples were collected in the Belgian part of the North Sea (BPNS). The area is situated in the Southern Bight of the North Sea and is mainly characterized by the presence of sandbank systems (Degraer et al. 1999). The BPNS further comprises $65 \mathrm{~km}$ of sandy beaches (Degraer et al. 2003). Given its high soft-sediment habitat heterogeneity, a wide variety of macrobenthos can be encountered. Four widely spread macrobenthic communities are present on the BPNS: (1) the muddy, fine sand Abra alba-Mysella bidentata community, e.g. location AM, (2) the Nephtys cirrosa community, occurring in well-sorted fine to medium sandy sediments, e.g. locations $\mathrm{N} 1$ and N2, (3) the Ophelia limacina-Glycera lapidum community, found in coarse sandy sediments, e.g. location OG, and (4) the Eurydice pulchra-Scolelepis squamata community, typical of the upper intertidal part of sandy beaches, e.g. location ES (Van Hoey et al. 2004). The area thus provides the opportunity to investigate the effects of sieving procedure for a wide range of soft-sediment macrobenthic species and communities, typical of the southern part of the North Sea.

The effects of sieving procedure were investigated at all four communties (1) to include a maximum suite of macrobenthic species, and (2) to evaluate the community-specific effects on diversity, density and community structure. The position of the sampling stations was selected from knowledge of the spatial distribution of the macrobenthic communities (subtidal: Van Hoey et al. 2004; intertidal: Degraer et al. 2003).

\section{Experimental setup}

In spring 2003, the three mentioned subtidal stations (AM, N1 and OG) and one intertidal station (ES) were sampled by means of a Van Veen grab or through excavation of a frame, respectively (sampling surface area $0.1 \mathrm{~m}^{2}$ ). The average median grain size of the four stations was $179 \mu \mathrm{m}(\mathrm{AM}), 237 \mu \mathrm{m}(\mathrm{N} 1), 487 \mu \mathrm{m}(\mathrm{OG})$ and $224 \mu \mathrm{m}(\mathrm{ES})$. 
At each station, ten samples were collected. In the subtidal zone all samples were collected randomly, while in the intertidal zone the samples were positioned parallel to the waterline (Fig. 1). Five samples were fixated immediately with an $8 \%$ formaldehydeseawater solution. In the subtidal environment the samples to be sieved alive and after fixation were selected randomly, while in the intertidal zone each sample to be sieved after fixation was collected next to a sample to be sieved alive. At minimum one hour after fixation (no living individuals observed), all samples were sieved over a $1 \mathrm{~mm}$ mesh sized sieve and preserved with an $8 \%$ formaldehyde-seawater solution.

Data was also available from seven stations, sampled in summer 1994. These stations were positioned along a transect parellel to the coastline (one location: stations at $100 \mathrm{~m}$ distance from each other) (Fig. 1). All these stations were located within the $N$. cirrosa community (location N2) and were sampled with four Van Veen grab replicates (sampling surface area $0.1 \mathrm{~m}^{2}$ ) each. One day before sieving over a $1 \mathrm{~mm}$ sieve, two randomly selected replicates were fixed with an $8 \%$ formaldehyde-seawater solution.

After staining with Bengal Rose all organisms were sorted, identified to species level (except for the oligochaetes) and counted.

\section{Data analysis}

Because of non-representative sampling, non-macrobenthic species (e.g. fish larvae) and rare species (maximum density 1 ind. sample ${ }^{-1}$ within maximally two samples) were excluded from the dataset prior to further analyses.

At the diversity level the effects of sieving procedure were investigated on several commonly used diversity measures: species richness, Hill's $\mathrm{N}_{1}, \mathrm{~N}_{2}$ and $\mathrm{N}_{\infty}$, Shannon-Wiener diversity index $\mathrm{H}^{\prime}, \mathrm{ES}_{100}$ and Pielou's eveness $\mathrm{J}^{\prime}$. To increase the reliability of the results, effects of sieving procedure on higher taxon- and species-specific densities were analysed for all higher taxa and

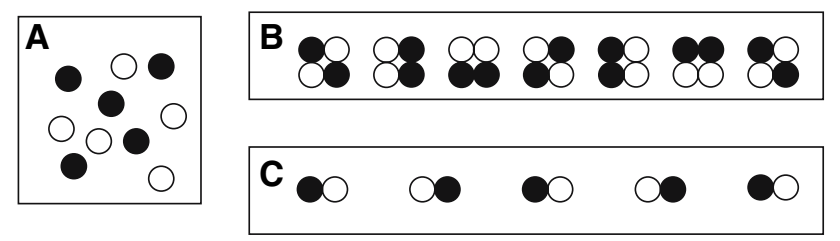

Fig. 1 Sampling strategies. a Replicated random sampling at one location (AM, N1 and OG). b Replicated random sampling at a series of locations (N2). c Unreplicated sampling at a series of sites (ES). Filled circles sample to be sieved after fixation, empty circles sample to be sieved alive species with an average density of at least 10 ind. $\mathrm{m}^{-2}$ in the samples fixated before sieving, using the location at which the species reached its highest density (i.e. maximisation of representativeness).

The statistical significance of the effects on diversity and density within each of the sampling locations was analysed with a Mann-Whitney $U$ test (independent samples: locations AM, N1 and OG) or a Wilcoxon matched-pairs test (dependent samples: locations N2 and ES). For location N2 each pair of samples sieved before fixation and sieved alive at the individual stations were both averaged prior to statistical analysis. Statistical significance was kept at $5 \%$.

The relationship between the effects of sieving procedure and the maximum length of the species was investigated through regression analysis. Although a better correlation between individual length and sieving procedure effect might be expected, we deliberately decided to base our regression analysis on species' maximum lengths: information on the species' lengthfrequency distributions within a sample is seldomly available, while maximum lengths can easily be taken from literature. The maximum length of the species under consideration was taken from literature (polychaetes: Hartmann-Schröder 1996; amphipods: Lincoln 1979; bivalves: Tebble 1966; echinoderms, Hayward and Ryland 1995). The length of juvenile Nephtys spp. was set at $10 \mathrm{~mm}$. The polychaete family Saccocirridae and oligochaetes were excluded because of the wide variety of maximum lengths of the different species within these taxa.

To investigate the effects of sieving procedure on the observed community structure, the data was subjected to TWINSPAN, both on density data (cutlevels: 0,10 , 50, 100 and 500 ind. $\mathrm{m}^{-2}$ ) and presence/absence data. Statistical significance of the multivariate difference between samples fixated before sieving and samples sieved alive at each sampling location was analysed through ANOSIM, using both density and presence/ absence data.

\section{Results}

Impacts at the diversity level

Except for Pielou's eveness $\mathrm{J}^{\prime}$, all diversity measures at the locations AM, N1, N2 and OG were higher in the samples sieved after fixation compared to the samples sieved alive (Table 1). At these locations the relative loss largely depended on diversity measure and location under consideration: the lowest relative loss was found for Shannon-Wiener $\mathrm{H}^{\prime}$ at location AM (3\%), 
Table 1 Quantification of the sieving strategy effect on commonly used diversity measures, average macrobenthic density (All) and taxon densities ( $A$ Amphipoda, $B$ Bivalvia, $C$ Cephalochordata, $E$ Echinodermata, $O$ Oligochaeta, $P$ Polychaeta) (ind. $\mathrm{m}^{-2}$ )

\begin{tabular}{|c|c|c|c|c|c|c|c|c|c|c|c|c|c|c|c|}
\hline & \multicolumn{3}{|l|}{$\mathrm{AM}$} & \multicolumn{3}{|l|}{ N1 } & \multicolumn{3}{|l|}{ N2 } & \multicolumn{3}{|l|}{ OG } & \multicolumn{3}{|l|}{ ES } \\
\hline & $\mathrm{F}$ & A & RL & $\mathrm{F}$ & A & RL & $\mathrm{F}$ & A & RL & $\mathrm{F}$ & A & RL & $\mathrm{F}$ & A & RL \\
\hline $\mathrm{S}$ & 13 & 12 & 12 & 7 & 6 & 9 & $8>$ & 6 & 30 & 7 & 6 & 24 & 2 & 2 & 0 \\
\hline $\mathrm{N}_{1}$ & 5.9 & 5.4 & 8 & 5.0 & 4.6 & 7 & $5.2>$ & 3.4 & 35 & 4.8 & 4.4 & 9 & 1.1 & 1.1 & 0 \\
\hline $\mathrm{N}_{2}$ & 4.1 & 3.8 & 7 & 4.1 & 3.8 & 8 & 4.0> & 2.6 & 35 & 4.0 & 3.7 & 9 & 1.0 & 1.0 & 0 \\
\hline $\mathrm{N}_{\infty}$ & 2.7 & 2.5 & 7 & 2.8 & 2.5 & 11 & 2.5> & 1.9 & 27 & 2.9 & 2.5 & 15 & 1.0 & 1.0 & 0 \\
\hline $\mathrm{H}^{\prime}$ & 2.5 & 2.4 & 3 & 2.3 & 2.2 & 6 & $2.4>$ & 1.7 & 26 & 2.2 & 2.1 & 4 & 0.1 & 0.1 & 6 \\
\hline $\mathrm{E} S_{100}$ & 11 & 10 & 7 & 7 & 6 & 8 & $8>$ & 6 & 28 & 7 & 5.6 & 20 & 2 & 2 & 2 \\
\hline $\mathrm{J}^{\prime}$ & 0.6 & 0.7 & -1 & 0.8 & 0.8 & 2 & $0.8>$ & 0.7 & 10 & 0.8 & 0.9 & -17 & 0.1 & 0.1 & 4 \\
\hline All & 1370 & 945 & 31 & 355> & 179 & 50 & 605 & 335 & 40 & $756>$ & 164 & 78 & 2975> & 2263 & 24 \\
\hline A & - & - & - & 121> & 58 & 52 & $52>$ & 35 & 32 & - & - & - & 39 & 25 & 35 \\
\hline B & 456 & 450 & 1 & - & - & - & - & - & - & - & - & - & - & - & - \\
\hline $\mathrm{C}$ & - & - & - & - & - & - & - & - & - & 10 & 4 & 60 & - & - & - \\
\hline $\mathrm{E}$ & 14 & 8 & 43 & - & - & - & - & - & - & 35 & 23 & 33 & - & - & - \\
\hline $\mathrm{O}$ & - & - & - & - & - & - & - & - & - & 31 & 0 & 100 & - & - & - \\
\hline $\mathrm{P}$ & 895> & 483 & 46 & $226>$ & 113 & 50 & 538> & 290 & 46 & $674>$ & 129 & 81 & 2932> & 2236 & 24 \\
\hline
\end{tabular}

Density decrease relative to fixed sieving density (\%)

Significant effects (bold) are marked with ">"

$F$ sieved after fixation, $A$ sieved alive, $R L$ relative loss

while the highest relative loss was encountered for $\mathrm{N}_{2}$ at location $\mathrm{N} 2(35 \%)$. The observed impact, however, was only found to be significant at location N2. At location ES all diversity measures were hardly impacted by the sieving procedure (relative loss: 0 up to $6 \%$ ). Pielou's eveness $\mathrm{J}^{\prime}$ showed the largest relative loss variability between locations ( -17 to $10 \%)$.

In general $k$-dominance curves of samples sieved after fixation or sieved alive showed a disjunct pattern at all locations (Fig. 2), except for location ES (composed of only three species). At locations AM and N2, the $k$-dominance curve of the samples sieved alive was situated above the curve of the samples sieved after fixation (i.e. sieving alive rendering a lower diversity), while the opposite trend was observed at locations N1 and OG.

Impacts at the density level

At all locations macrobenthic density was lower in samples sieved alive compared to samples sieved after fixation (Table 1): relative loss varied between $24 \%$ (location ES) and 78\% (location OG). A significant effect was found at locations N1, OG and ES. Higher
Fig. 2 Effect of sieving procedure on the communities' $k$-dominance curves. a Abra alba-Mysella bidentata community (AM). b Nephtys cirrosa community (left $\mathrm{N} 1$, right N2). c Ophelia limacinaGlycera lapidum community (OG). d Eurydice pulchraScolelepis squamata community (ES). Filled circles sieving after fixation, empty circles sieving alive
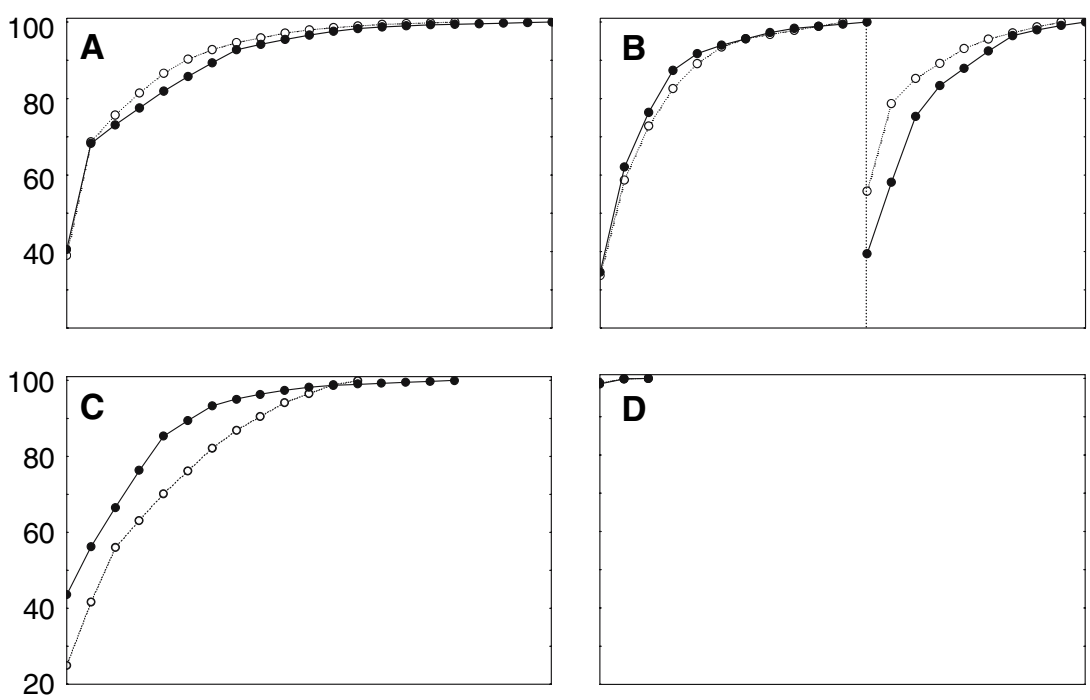
taxon densities were always lower in the samples sieved alive compared to those sieved after fixation. The relative loss of the density at the taxon level varied between 1\% (bivalves at location AM) and 100\% (oligochaetes at location $\mathrm{N} 2$ ). A significant relative loss was encountered for amphipods (locations N1 and N2) and for polychaetes (all locations).

A total of 28 species was tested for the effect of sieving procedure (treshold density: 10 ind. $\mathrm{m}^{-2}$ in the samples sieved after fixation), four of which being amphipods, three bivalves, two echinoderms, 18 polychaetes and one cephalochordate (Table 2). Relative loss at the species level varied between -20 (the bivalve Abra alba) to $100 \%$ (the echinoderm Leptosynapta minuta and the polychaetes Hesionura elongata, Spio filicornis and Saccocirridae sp.). Significant relative losses were found in the amphipods $(50 \%$ of the species) and the polychaetes (39\% of the species). The effect of sieving procedure on densities largely depended on the higher taxon under consideration
(Table 3): all bivalve species were considered to be non-affected (relative loss class: -20 to $20 \%$ ), whereas polychaete species were affected to variable degree (relative loss class: -20 to 20 up to 80 to $100 \%$ ).

Relative loss at the species density level was negatively correlated with the maximum species length as taken from literature (Fig. 3). However, this relationship was only significant $(P=0.0009)$ and explaining a substantial part of the variability within the data $\left(R^{2}=0.53\right)$ for the polychaete species, allowing to set up a regression model solely for this taxon:

Polychaetes' relative loss $(\%)=0.8738( \pm$ SE 0.0959$)$ $-0.0029( \pm$ SE 0.0007$) \times$ maximum length $(\mathrm{mm})$

Impacts at the level of community structure

Irrespective of sieving procedure, all samples were grouped per location, when performing a TWINSPAN based on absolute density, as well as on presence/ absence data (Fig. 4). A distinction between samples
Table 2 Quantification of the sieving strategy effect on the species densities
Loc., location at which the species attained highest density; mean, mean-density (ind. $\mathrm{m}^{-2}$ ); Relative loss, density decrease relative to fixed sieving density ( $\%$ ); Stat. sign., statistical significance $(P$ value) of the effect; $S E$ standard error (ind. $\mathrm{m}^{-2}$ )

\begin{tabular}{|c|c|c|c|c|c|c|c|}
\hline & \multirow[t]{2}{*}{ Loc. } & \multicolumn{2}{|c|}{ Fixed sieving } & \multicolumn{2}{|c|}{ Alive sieving } & \multirow[t]{2}{*}{ Relative loss } & \multirow[t]{2}{*}{ Stat. sign. } \\
\hline & & Mean & SE & Mean & SE & & \\
\hline \multicolumn{8}{|l|}{ Amphipoda } \\
\hline Pontocrates arenarius & N1 & 16 & 5 & 2 & 2 & 88 & 0.043 \\
\hline Bathyporeia guilliamsoniana & $\mathrm{N} 1$ & 97 & 16 & 45 & 14 & 54 & 0.035 \\
\hline Bathyporeia pilosa & ES & 29 & 13 & 25 & 6 & 14 & 0.500 \\
\hline Pontocrates altamarinus & $\mathrm{N} 2$ & 24 & 4 & 22 & 5 & 8 & 0.866 \\
\hline \multicolumn{8}{|l|}{ Bivalvia } \\
\hline Fabulina fabula & $\mathrm{AM}$ & 380 & 66 & 368 & 42 & 3 & 0.917 \\
\hline Donax vittatus & $\mathrm{AM}$ & 60 & 16 & 66 & 22 & -10 & 0.596 \\
\hline Abra alba & $\mathrm{AM}$ & 10 & 8 & 12 & 4 & -20 & 0.381 \\
\hline \multicolumn{8}{|l|}{ Echinodermata } \\
\hline Leptosynapta minuta & OG & 29 & 27 & 0 & & 100 & 0.136 \\
\hline Ophiura ophiura & $\mathrm{AM}$ & 14 & 4 & 8 & 4 & 43 & 0.268 \\
\hline \multicolumn{8}{|l|}{ Polychaeta } \\
\hline Hesionura elongata & OG & 96 & 42 & 0 & & 100 & 0.018 \\
\hline Spio filicornis & $\mathrm{N} 2$ & 113 & 29 & 0 & & 100 & 0.018 \\
\hline Saccocirridae sp. & OG & 14 & 13 & 0 & & 100 & 0.317 \\
\hline Polygordius appendiculata & OG & 329 & 152 & 6 & 4 & 98 & 0.008 \\
\hline Spiophanes bombyx & $\mathrm{N} 2$ & 49 & 8 & 5 & 3 & 90 & 0.018 \\
\hline Eumida sanguinea & $\mathrm{AM}$ & 19 & 13 & 2 & 2 & 89 & 0.065 \\
\hline Sphaerosyllis hystrix & OG & 68 & 51 & 10 & 6 & 85 & 0.228 \\
\hline Pisione remota & OG & 74 & 46 & 12 & 12 & 84 & 0.118 \\
\hline Eteone longa & $\mathrm{N} 2$ & 27 & 5 & 13 & 5 & 52 & 0.028 \\
\hline Nephtys juvenile & $\mathrm{N} 1$ & 123 & 17 & 60 & 9 & 51 & 0.027 \\
\hline Magelona johnstoni & $\mathrm{AM}$ & 556 & 145 & 281 & 28 & 49 & 0.094 \\
\hline Glycera lapidum & $\mathrm{OG}$ & 78 & 14 & 41 & 17 & 47 & 0.094 \\
\hline Nephtys assimilis & $\mathrm{AM}$ & 18 & 7 & 12 & 7 & 33 & 0.511 \\
\hline Sigalion mathildae & $\mathrm{AM}$ & 49 & 18 & 35 & 7 & 29 & 0.831 \\
\hline Nephtys cirrosa & $\mathrm{N} 2$ & 104 & 18 & 77 & 8 & 26 & 0.173 \\
\hline Scolelepis squamata & ES & 2932 & 271 & 2236 & 247 & 24 & 0.043 \\
\hline Lanice conchilega & $\mathrm{AM}$ & 60 & 31 & 49 & 22 & 18 & 1.000 \\
\hline Nephtys hombergii & $\mathrm{AM}$ & 47 & 5 & 55 & 9 & -17 & 0.512 \\
\hline \multicolumn{8}{|l|}{ Cephalochordata } \\
\hline Branchiostoma lanceolatum & $\mathrm{OG}$ & 4 & 10 & 4 & 8 & 60 & 0.521 \\
\hline
\end{tabular}


Table 3 Impact of sieving strategy at the taxon level: number (Abs.) and percentage (Rel.) of species allocation to five relative loss classes

\begin{tabular}{|c|c|c|c|c|c|c|c|c|c|c|}
\hline \multirow[t]{3}{*}{ Relative loss } & \multirow{2}{*}{\multicolumn{2}{|c|}{$\frac{\text { Non-affected }}{-20 \text { to } 20 \%}$}} & \multicolumn{8}{|c|}{ Affected } \\
\hline & & & \multicolumn{2}{|c|}{20 to $40 \%$} & \multicolumn{2}{|c|}{40 to $60 \%$} & \multicolumn{2}{|c|}{60 to $80 \%$} & \multicolumn{2}{|c|}{80 to $100 \%$} \\
\hline & Abs. & Rel. & Abs. & Rel. & Abs. & Rel. & Abs. & Rel. & Abs. & Rel. \\
\hline Amphipoda & 2 & 50 & & & 1 & 25 & & & 1 & 25 \\
\hline Bivalvia & 3 & 100 & & & & & & & & \\
\hline Echinodermata & & & & & 1 & 50 & & & 1 & 50 \\
\hline Polychaeta & 2 & 11 & 4 & 22 & 4 & 22 & & & 8 & 44 \\
\hline Cephalochordata & & & & & & & 1 & 100 & & \\
\hline Total & 4 & 14 & 4 & 14 & 6 & 21 & 1 & 3 & 11 & 38 \\
\hline
\end{tabular}

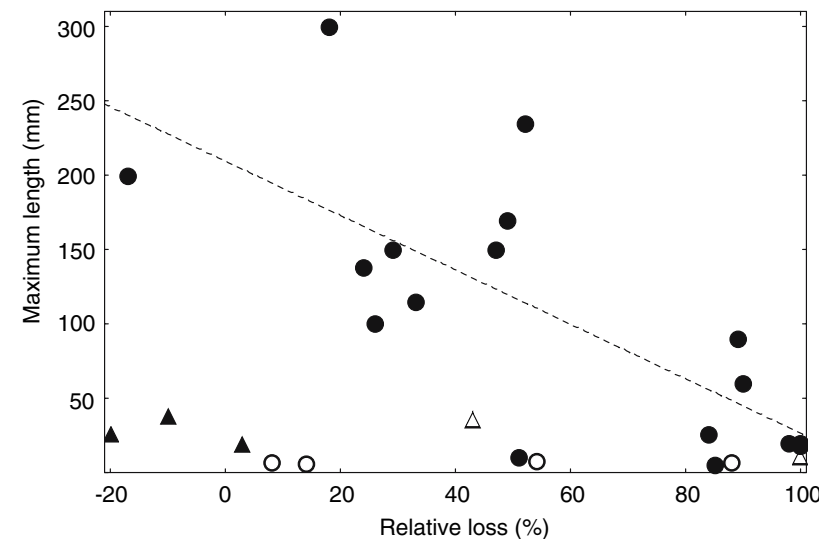

Fig. 3 Relative loss as a function of species-specific maximum lengths taken from literature. Filled circles Polychaeta (including linear regression model), empty circles Amphipoda, Filled triangle Bivalvia, empty triangle Echinodermata

sieved after fixation and samples sieved alive largely depended on the location and type of analysis.

When running TWINSPAN on absolute density data, a sieving procedure effect was detected at location OG (perfect discrimination) and to a lesser extent at location N2. ANOSIM, based on absolute density data, showed a multivariate dissimilarity between sam- ples sieved after fixation and samples sieved alive varying between 17\% (ES) and 85\% (OG) (Table 4). Significant effects were observed at all locations, except for ES. Eighty-three percent of all species contributing to the significant multivariate effects of sieving procedure for more than $20 \%$ belonged to the polychaetes.

TWINSPAN on presence/absence data showed no obvious effect of sieving procedure (Fig. 4). ANOSIM, based on presence/absence data, showed a multivariate dissimilarity between samples sieved after fixation and samples sieved alive varying between 6\% (ES) and $63 \%$ (OG) (Table 4). Significant effects were only observed at the locations N2 and OG. One species, the polychaete $S$. filicornis, contributed to the significant multivariate effects of sieving procedure for more than $20 \%$ (location N2).

\section{Discussion}

Impacts at the diversity level

Sieving procedure clearly impacts diversity measures, as demonstrated by the generally higher values when
Fig. 4 TWINSPAN dendrograms based on absolute densities and based on presence/ absence data, with indication of the multivariate relation between communities (locations AM, N1, N2, OG and ES) as well as between samples sieved after fixation (F) and sieved alive (A). Percentages refer to the relative allocation of the respective replicate samples

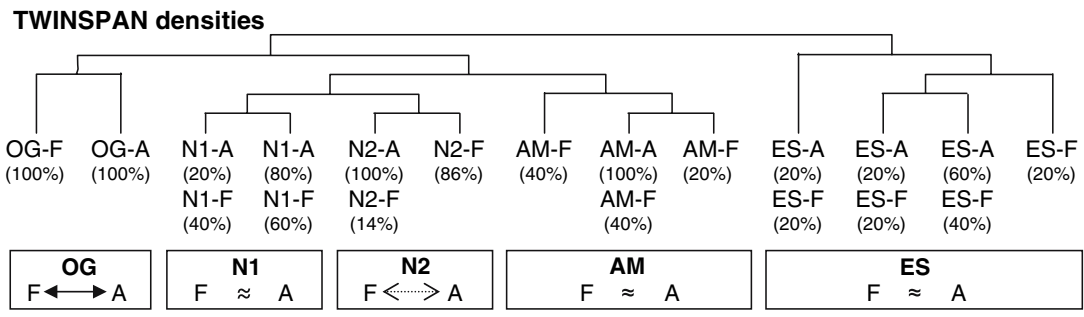

TWINSPAN presence/absence

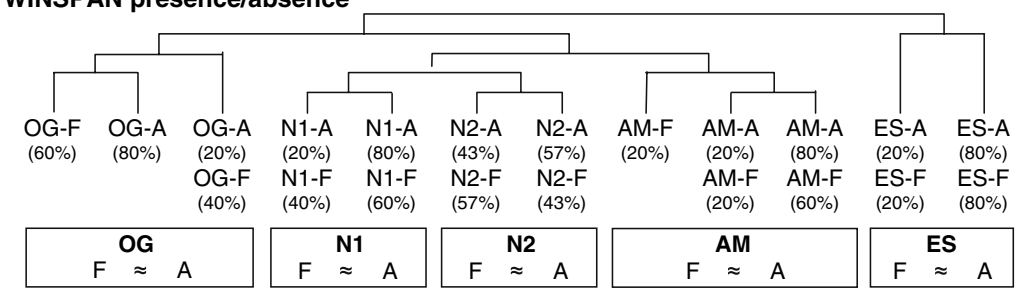


Table 4 Multivariate dissimilarity between samples sieved after fixation and samples sieved alive at all locations as analysed through ANOSIM ( $R$ statistic and $P$ value), based on absolute density and presence/absence data

\begin{tabular}{|c|c|c|c|c|c|}
\hline & $R$ statistic & $P$ value & $\begin{array}{l}\text { Average } \\
\text { dissimilarity } \\
(\%)\end{array}$ & $\begin{array}{l}\text { Prominent } \\
\text { discriminating } \\
\text { species }\end{array}$ & \\
\hline \multicolumn{6}{|c|}{ Absolute densities } \\
\hline $\mathrm{AM}$ & 0.256 & 0.048 & 33 & Magelona johnstoni & 38 \\
\hline N1 & 0.426 & 0.024 & 44 & $\begin{array}{l}\text { Nephtys juvenile } \\
\text { Bathyporeia } \\
\text { guilliamsoniana }\end{array}$ & $\begin{array}{l}27 \\
25\end{array}$ \\
\hline $\mathrm{N} 2$ & 0.323 & 0.001 & 49 & $\begin{array}{l}\text { Magelona johnstoni } \\
\text { Spio filicornis }\end{array}$ & $\begin{array}{l}35 \\
23\end{array}$ \\
\hline OG & 0.646 & 0.008 & 85 & $\begin{array}{l}\text { Polygordius } \\
\text { appendiculata }\end{array}$ & 38 \\
\hline ES & 0.146 & 0.143 & 17 & - & - \\
\hline \multicolumn{6}{|c|}{ Presence/absence } \\
\hline $\mathrm{AM}$ & 0.060 & 0.317 & 23 & - & - \\
\hline N1 & 0.148 & 0.167 & 32 & - & - \\
\hline N2 & 0.414 & 0.001 & 29 & Spio filicornis & 25 \\
\hline OG & 0.402 & 0.008 & 63 & None & - \\
\hline ES & -0.080 & $>0.999$ & 6 & - & - \\
\hline
\end{tabular}

Prominent discriminating species are those contributing for more than $20 \%$ to significant dissimilarities (with indication of their contribution \%)

sieving after fixation: statistically significant relative losses as high as $35 \%$ were observed. However, most losses were statistically non-significant. The loss was largely community-dependent, with the intertidal E. pulchra-S. squamata community showing the lowest losses.

Although an impact of sieving procedure at the level of diversity measures was detected, no unambiguous trend could be observed considering the $k$-dominance curves. These ambiguous impacts might be explained by the complexity of the diversity measures: except for the species richness, each diversity measure takes into account species richness as well as eveness. When a dominant species, for instance, decreases in density, eveness and thus all eveness-based diversity measures within the sample will increase, while when the same species completely disappears because of the sieving procedure, eveness will increase as well, but in the mean time species richness will decrease. In the latter case, the final impact on diversity (from negative to positive) will depend on the total number of species and the eveness of all species in the sample. As such the impact of sieving procedure on diversity will mainly be determined by the differential impact on the individual species, as discussed in the next sections.

Impacts at the density level

The impact of sieving procedure on macrobenthic density at all locations is caused primarily by the high relative losses of polychaetes (24-81\%, significant at all locations), the most dominant taxon at the locations under consideration. To a lesser extent also amphipods contributed to the impact on macrobenthic density (32-52\%, significant at two locations). Because of their rigid shells, bivalves, being the third abundant taxon, cannot actively escape through the meshes and are thus not impacted by sieving procedure.

Eight out of eighteen polychaete species investigated showed a relative loss of more than $80 \%$ (significant for four species), all of these being interstitial (Sphaerosyllis hystrix, H. elongata, Pisione remota, Polygordius appendiculatus and Saccocirridae sp.) or other small species (S. filicornis, Spiophanes bombyx and Eumida sanguinea) (Hartmann-Schröder 1996: $<30 \mathrm{~mm}$ ). Larger polychaetes, such as Nephtys spp., were less impacted by sieving procedure (relative loss: $<30 \%$ ). Regression analysis confirmed the negative correlation between polychaete length (taken from literature) and relative loss. On the other hand only one larger polychaete species, Scolelepis squamata, showed a significant difference. Next to the length, also the shape and behaviour-among other factors-of the animal seem to play an important role (Thompson et al. 2003): S. squamata is a long and slender polychaete with a pointed head, used to quickly burrow into the sandy beach after being washed out (Hartmann-Schröder 1996). Thompson et al. (2003) also found a high retention of polychaetes with obvious head capsules or with particularly large appendages. This might explain the non-significant effect on the density of Magelona johnstoni, a rather small (maximum length generally $<50 \mathrm{~mm}$ ) and slender polychaete, but having a pair of long palps (Hartmann-Schröder 1996).

Interstitial and other small polychaetes, e.g. S. hystrix, H. elongata, P. remota, P. appendiculatus, E. longa, juvenile Nephtys spp., S. bombyx and S. filicornis show a considerable difference between the two ways of sieving. For those species in particular caution is needed when comparing different results. Van Hoey et al. (2004) already mentioned that the interstitial polychaetes were strongly underestimated in his study compared to former descriptions of the same community by Govaere (1978), revealing high densities of interstitial polychaetes (up to 800 ind. $\mathrm{m}^{-2}$ ) and that this might be explained by differences within the post-sampling treatment: sieving after fixation versus sieving alive, allowing the interstitial polychaetes to escape actively through the sieve. Vanosmael et al. (1982) also sieved her samples after fixation and found very high densities of interstitial polychaetes. It has yet to be taken into account that the samples of Govaere (1978) and Vanosmael et al. (1982) were sieved over a smaller 
mesh. When sieves are used with a smaller mesh size, the densities of interstitial and small polychaetes will consequently be higher as most of these species may crawl through a $1 \mathrm{~mm}$ sieve, but not through a finer meshed sieve. As a consequence sieve mesh size and sieving procedure could be considered as closely interacting with each other: using a smaller mesh sized sieve could nullify the losses due to sieving alive. It has yet to be taken into account that the sieving procedure will take more time when a smaller sieve is used, with a consequent longer period of time for animals to try to escape. As it is recommended that biomass estimates should ideally be obtained from un-preserved specimens, because biomass changes due to fixation (Mills et al. 1982; Pakhomov 2003), and because sieving is often done alive because of logistic reasons (Bilyard et al. 1987; Pohle and Thomas 1997), the use of a smaller sieve mesh size (e.g. mesh size: $0.5 \mathrm{~mm}$ ) might be the best option. It is, however, important to consider that, since there is no clear cut size differentiation between meio- and macrobenthos, a smaller sieve mesh size will also retain more individuals of species, typically allocated to the meiofauna (e.g. nematodes). This will again have its consequences for the data set compatibility.

Impacts at the level of community structure

Our study showed that sieving procedure might impact community structure. This impact, however, largely depended on the community (location) under consideration as well as the level of detail used to perform the multivariate analysis (absolute densities versus presence/absence data). At the locations ES, AM and N1, no impact was detected on the community structure based on absolute densities nor on presence/absence data, whereas community structure was impacted at the locations OG and $\mathrm{N} 2$, only when using the absolute densities. ANOSIM results confirmed the differentiation of impact between the different locations, with the highest dissimilarities at locations OG and N2 (absolute densities: 85 and 49\%, respectively). The major impact results from the high relative loss of some of the most dominant species at both locations: $P$. appendiculata (location OG) and $M$. johnstoni and S. filicornis (location N2), each of these species accounting for more than $20 \%$ of the dissimilarity between samples sieved after fixation versus samples sieved alive. As discussed above, these species are heavily impacted by sieving procedure (small and actively escaping polychaetes) and might thus strongly influence multivariate community structure.
The impact of sieving procedure on the community structure was subordinate to the general differentiation between the communities: multivariate analyses aggregated all samples per location, each representing a separate community. Contrary to (detailed) community composition features, no major impact of sieving procedure should be expected when aiming at distinguishing between different communities (f.i. investigation of community distribution patterns).

The differentiation of impact between locations might further be strenghtened because of the correlation between sediment particle size and handling time when sieving: a larger particle size (location OG) generally implies a longer sieving period and macrobenthic species thus have more time to actively escape through the meshes of the sieve. It is, however, impossible to distinguish between the contribution of species-specific capabilities to escape and the contribution of handling time when sieving, since many species, showing a high relative loss in this study (e.g. interstitial polychaetes), typically inhabit coarse sandy sediments (Van Hoey et al. 2004). However, acknowledging that handling time might lead to a decrease of (species) density, it is important to keep handling time when sieving as short as possible. Thorson (1957) mentioned that even larger individuals may be lost during prolonged sieving.

We further acknowledge the fact that the impact at the community level was tested only within nearshore communities, typically dominated by opportunistic, smaller species. Given the fact that mainly small species are heavily impacted by sieving procedure, communities dominated by larger species, such as offshore and deep-water communities, are expected to be less impacted. A careful consideration of the community's species composition, with respect to their size distribution, is thus advised.

Other elements influencing the effect of sieving procedure

Also the water depth of the sampling station is an important factor determining whether a difference between the both sieving procedures might occur. Gage et al. (2002) mentioned that differences between sieving a sample alive or after fixation, might occur in samples from shallow water, where the movement or posture of living animals may affect the operation of the sieve, but this would not normally occur within deep sea samples because the animals are generally dead by the time they reach the surface.

Whether there actually is a difference between sieving a sample alive or after fixation also depends on the sampling season. If some species are in the settlement 
or recruitment phase at the time of sampling, many small individuals will be collected and thus more species might crawl through the sieve actively. Conversely, if the samples are collected out of the breeding season, the number of small specimens would be fewer (Ohwada 1988) and the difference in density between the two ways of sieving for that species will be less. Thompson et al. (2003) for example found that the abundance of the crustaceans was underestimated in the $1 \mathrm{~mm}$ fraction and concluded that this may have occurred because sampling took place during summer when greater numbers of small juveniles are present. This demonstrates the importance of sieve mesh size and sieving procedure when aiming at the investigation of the macrobenthic population dynamics.

The period of fixation time prior to sieving is expected to be of minor importance: as soon as the animals are dead, which happens within at maximum $15 \mathrm{~min}$, their active escape, which is the main cause of the impact, is prevented. Longer periods of fixation, however, might cause the animals to become more rigid. Although not shown in this paper, we hypothesize that rigid, compared to slack individuals have a smaller chance of passively passing through the sieve. Compared to the impact of fixation before sieving, this impact is however considered of minor importance. A such, the use of narcotics (e.g. $\mathrm{MgCl}_{2}$ ) before sieving, preventing an active escape, but keeping the individuals slack, is expected to have a similar impact as the use of fixatives.

\section{Conclusions and recommendations}

This study indicated that sieving procedure does impact macrobenthos studies at the level of diversity, density, as well as community structure. As a conclusion of this study we recommend to consider the following findings when evaluating data compatibility:

1. The magnitude of impact of sieving procedure was lower at the level of diversity, compared to the levels of density and community structure.

2. Because of the complexity of diversity measures, taking into account both species richness and eveness, the impact of sieving procedure at the level of diversity is ambiguous: both increasing and decresing diversity measures were observed in this exercise.

3. Caution is needed in particular when working in areas and communities dominated by small, interstitial and/or larger, slender polychaetes, such as nearshore environments. Larger polychaetes, polychaetes with obvious head capsules and appendages and more rigid species, such as amphipods and bivalves, are less prone to the impact. A careful consideration of the species composition, with respect to their size distribution, is thus advised.

4. Although sieving procedure was always subordinate to the general differentiation between the communities, a community-dependent impact on the detailed community structure should not be neglected.

5. The overall impact of sieving procedure is expected to be particularly strong when collecting samples during the macrobenthic recuitment period, when small juvenile specimes are abundantly present. One is thus advised to be particularly careful when investigating macrobenthic population dynamics.

6. Sieve mesh size and sieving procedure are considered as closely interacting: using a smaller mesh sized sieve could nullify the losses due to sieving alive. However, the use of a finer sieve is also expected to retain more typically meiobenthic taxa, such as nematodes.

The present study thus demonstrated that combining data, retrieved with a different sieving procedure can be useful, but its reliability will mainly depend on the type of questions one wants to answer with the data. In all cases caution at all levels of ecological organisation is advised.

Acknowledgments This paper is based on thesis research performed within the MSc programme "Marine and Lacustrine Sciences", organised by Ghent University (Belgium). Valuable comments on a first draft of the paper were provided by R. Callaway (University of Wales, Swansea). The authors acknowledge B. Beuselinck (Ghent University) for his help during the sampling and D. Schram (Ghent University) for the sediment analysis. The additional data were collected within the framework of the EU-RIACON project (Ref. No. P102/41SC4294). We further thank E. Rachor and another anonymous referee for their constructive remarks on the paper.

\section{References}

Bachelet G (1990) The choice of a sieving mesh size in the quantitative assessment of marine macrobenthos: a necessary compromise between aims and constraints. Mar Environ Res 30:21-35

Bilyard G, Becker S, Striplin P, Word J (1987) Recommended protocols for sampling and analysing subtidal benthic macroinvertebrate assemblages in Puget sound. US EPA, Report, TC-3391-04, 31

Cooper KM, Boyd SE (2002) Approaches to processing benthic samples. In: Boyd SE (ed) Guidelines for the conduct of benthic studies at aggregate dredging sites. Centre for Environment, Fisheries and Aquaculture Science on behalf of the 
Department for transport, local government and the regions, UK

Degraer S, Vincx M, Meire P, Offringa H (1999) The macrozoobenthos of an important wintering area of the common Scoter (Melanitta nigra). J Mar Biol Assoc UK 79:243-251

Degraer S, Volckaert A, Vincx M (2003) Macrobentic zonation patterns along a morphodynamical continuum of macrotidal, low tide bar/rip and ultra-dissipative sandy beaches. Est Coast Shelf Sci 56:459-468

Dybern BI, Ackfors H, Elmgren R (1976) Section 5: Benthic meiofauna and section 6: sampling of soft bottom macrofauna. In: Recommendations on methods for marine biological studies in the Baltic Sea. Baltic Marine Biologists Publication 1, Askö Laboratory, University of Stockholm, Sweden, pp 51-75

Eleftheriou A, Holme NA (1984) Macrofauna techniques. In: Holme NA, McIntyre AD (eds) Methods for the study of marine benthos, IBP Handbook No. 16. Blackwell, Oxford, pp 140-216

Elliott B, Degraer S, Bursey M, Vincx M (1996) Intertidal zonation of macroinfauna on a dissipative, sandy beach at De Panne (Belgium): a pilot study. Biol Jaarb Dodonaea 64:92-108

Gage JD, Hughes DJ, Gonzalez Vecino JL (2002) Sieve size influence in estimating biomass, abundance and diversity in samples of deep-sea macrobenthos. Mar Ecol Prog Ser 225:97-107

Govaere JCR (1978) Numerieke analyse van het makrobenthos in de Southern Bight (Noordzee). PhD thesis Ghent University, Ghent

Hartmann-Schröder G (1996) Annelida, Borstenwürmer, Polychaeta-Tierwelt Deutschlands, Teil 58. Gustav Fischer, Jena

Hayward PJ, Ryland JS (1995) Handbook of the marine fauna of North-West Europe. Oxford University Press, Oxford

James RJ, Lincoln Smith MP, Fairweather PG (1995) Sieve mesh size and taxonomic resolution needed to describe natural spatial variation of marine macrofauna. Mar Ecol Prog Ser 118:187-198

Künitzer A, Basford D, Craeymeersch JA, Dewarumez J-M, Dörjes J, Duineveld GCA, Eleftheriou A, Heip C, Herman $\mathrm{P}$, Kingston P, Niermann U, Rachor E, Rumohr H, Dewilde PAJ (1992) The benthic infauna of the North Sea: species distribution and assemblages. ICES J Mar Sci 49:127-143

Lincoln RJ (1979) British marine amphipoda; Gammaridea. British Museum (Natural History), London
Long BG, Wang YG (1994) Method for comparing the capture efficiency of benthic sampling devices. Mar Biol 121:397-399

McIntyre AD, Elliott JM, Ellis DV (1984) Introduction: design of sampling programmes. In: Holme NA, McIntyre AD (eds) Methods for the study of marine benthos, IBP handbook No. 16. Blackwell, Oxford, pp 1-26

Mills EL, Pittman K, Munroe B (1982) Effect of preservation on the weight of marine benthic invertebrates. Can J Fish Aquat Sci 39:221-224

Ohwada T (1988) Mesh size for settlement and recruitment studies of polychaetes with reference to the effect of fixation on washing bottom samples. Asian Mar Biol 5:35-40

Pakhomov EA (2003) Correction of zooplankton and benthos biomass under-estimations from formaldehyde-preserved samples. Arch Fish Mar Res 50:141-148

Pohle WP, Thomas MLH (1997) Monitoring protocol for marine benthos: intertidal and subtidal macrofauna. In: Pohle $G$ (ed) Marine and estuarine biodiversity monitoring protocols. Report to the Ecological Monitoring and Assessment Network, St Andrews, New Brunswick, pp 17-45

Rees H, Cochrane S, Craeymeersch J, de Kluijver M, Degraer S, Desroy N, Dewarumez J-M, Duineveld G, Essink K, Hillewaert H, Kilbride R, Kröncke I, Nehmer P, Rachor E, Reiss $\mathrm{H}$, Robertson $\mathrm{M}$, Rumohr $\mathrm{H}$, Vanden Berghe $\mathrm{E}$, Van Hoey G (2002). The North Sea benthos project: planning, management and objectives. ICES CM L(9):1-10

Rumohr H (1990) Soft bottom macrofauna: collection, treatment, and quality assurance of samples. ICES techniques in Environmental Sciences, No.8, Revised

Tebble N (1966) British bivalve seashells. A handbook for identification. Trustees of the British Museum, London

Thorson G (1957) Sampling the benthos. Mem Geol Soc Am 67:61-73

Thompson BW, Riddle MJ, Stark JS (2003) Cost-efficient methods for marine pollytion monitoring at Casey station, East Antarctica: the choice of sieve mesh size and taxonomic resolution. Mar Poll Bull 46:232-243

Van Hoey G, Degraer S, Vincx M (2004) Macrobenthic community structure of soft-bottom sediments at the Belgian Continental Shelf. Est Coast Shelf Sci 59:599-613

Vanosmael C, Willems KA, Claeys D, Vincx M, Heip C (1982) Macrobenthos of a sublittoral sandbank in the Southern Bight of the North Sea. J Mar Biol Assoc UK 62:521-534 